Article

\title{
A High-Gain Three-Port Power Converter with Fuel Cell, Battery Sources and Stacked Output for Hybrid Electric Vehicles and DC-Microgrids
}

\author{
Ching-Ming Lai * and Ming-Ji Yang \\ Department of Vehicle Engineering, National Taipei University of Technology, 1, Sec. 3, Chung-Hsiao E. Rd., \\ Taipei 106, Taiwan; mjyang@ntut.edu.tw \\ * Correspondence: pecmlai@gmail.com; Tel.: +886-2-2771-2171 (ext. 3612); Fax: +886-2-2731-4990 \\ Academic Editor: Michael Gerard Pecht \\ Received: 4 January 2016; Accepted: 4 March 2016; Published: 9 March 2016
}

\begin{abstract}
This paper proposes a novel high-gain three-port power converter with fuel cell (FC), battery sources and stacked output for a hybrid electric vehicle (HEV) connected to a dc-microgrid. In the proposed power converter, the load power can be flexibly distributed between the input sources. Moreover, the charging or discharging of the battery storage device can be controlled effectively using the FC source. The proposed converter has several outputs in series to achieve a high-voltage output, which makes it suitable for interfacing with the HEV and dc-microgrid. On the basis of the charging and discharging states of the battery storage device, two power operation modes are defined. The proposed power converter comprises only one boost inductor integrated with a flyback transformer; the boost and flyback circuit output terminals are stacked to increase the output voltage gain and reduce the voltage stress on the power devices. This paper presents the circuit configuration, operating principle, and steady-state analysis of the proposed converter, and experiments conducted on a laboratory prototype are presented to verify its effectiveness.
\end{abstract}

Keywords: fuel cell (FC); battery; hybrid electric vehicle (HEV); dc-microgrid; high-gain; three-port power converter with stacked output

\section{Introduction}

Because of the rapid increase in the global population and energy consumption, electric vehicles (EVs) that use clean energy sources connected to dc-microgrids have been proposed as favorable and environmentally friendly alternatives to conventional vehicles [1-5]. A dc-microgrid comprises a grid-connected converter (GCC), the different types of distributed energy generation systems, a battery storage system, EVs, and local emergency loads. The function of the GCC is to maintain a constant dc-bus voltage. To ensure the operational reliability of the dc-microgrid, a mass of battery storage devices is usually added to the system. EVs provide ancillary services to the dc-microgrid, which facilitates clean and efficient electric-powered transportation by enabling the EVs to power or be powered by the grid.

In hybrid electric vehicles (HEVs), fuel cell (FC) stacks can be used as clean energy sources. FCs are energy sources that directly convert chemical energy to electrical energy. FCs generate electric energy and, rather than storing it, continue to deliver the energy as long as the fuel supply is maintained. However, FCs have the drawbacks of slow dynamic response and high cost per output power [2,6-9]. Thus, FCs alone are not used in HEVs to satisfy load demands, particularly during startup and transient events. Therefore, to solve these problems, FCs are generally used with the battery storage device. Furthermore, the combined use of FCs and the battery storage device reduces hydrogen consumption in the FCs [3,6-9]. 
In general, FCs and batteries have different voltage levels. Therefore, to provide a specific voltage level for the load and control power flow between the input sources, a power converter is required for each of the input sources; this increases the price, mass, and losses. To overcome these drawbacks, multiport converters have been used in hybrid power systems [10-21]. These converters are of two main types: isolated and nonisolated. In isolated converters, high-frequency transformers are used to provide galvanic isolation. Several types of isolated converters, such as half-bridge, full-bridge, dual-active bridge, boost half-bridge, and combinational multiport isolated converters, have been investigated [10-17].

According to the literature, usage of nonisolated converters in EV applications is more useful. A multi-input buck converter was introduced in [20]. The advantage of this converter is that it reduces the number of inductors and capacitors, leading to lower converter cost, volume, and weight. However, lack of an effective power flow control between the input sources is a disadvantage. A multiphase converter was introduced in [21]. In this converter, each of the energy sources can deliver or absorb energy from the load and other sources. Using a separate inductor for each input source is a drawback of this converter. A triple input converter for hybridization of the battery, photovoltaic cells, and the FC was introduced in [22]. Appropriately switching this converter enables the charging and discharging of the battery through other sources and load, respectively. A systematic approach for deriving nonisolated multi-input converter topologies through a combination of buck, boost, Ćuk, and SEPIC was presented in [23]. A multi-input converter with only one inductor was proposed in [24]; this converter distributes the load power between the input sources and enables power transfer between the sources. A nonisolated multi-input-multi-output (MIMO) converter comprising only one inductor was introduced in [25]. However, this converter uses a high number of switches, which causes low efficiency. Moreover, the converter cannot transfer energy between the input sources. To overcome these drawbacks, a new nonisolated MIMO boost converter was proposed [26]. This converter is used in hybridizing clean energy sources in EVs. The basic boost converter is modified and integrated; however, in practice, the voltage gain of the MIMO boost converter is limited owing to the losses associated with the inductor, filter capacitor, main power switch, and rectifier diode. Because of a very high duty ratio, the output rectifier conducts for an extremely short time during each switching cycle, thus resulting in major reverse-recovery problems and an increase in the rating of the rectification diode. The switch-off loss due to the rectifier diode affects the efficiency, resulting in the electromagnetic interference problem that is severe in this condition.

This paper proposes a high-gain three-port power converter with FC, battery sources and stacked output for an HEV connected to a dc-microgrid. In the proposed converter, the load power can be flexibly distributed between the input sources. Moreover, the charging or discharging of a battery storage device can be controlled effectively using the FC source. The proposed converter comprises only one boost inductor integrated with a flyback transformer; the boost and flyback circuit output terminals are stacked to increase the output voltage gain, making it suitable for interfacing with dc-microgrid. The stacked output structure of the proposed converter enables all the voltage stresses of power devices to be distributed and reduced. Therefore, the high performance and relatively lower drain-source voltage (i.e., $V_{\mathrm{DS}}$ ) aids in further reducing both switching and conduction losses. This paper presents the circuit configuration, operating principle, and steady-state analysis of the proposed converter. The validity of the proposed power converter and its performance were verified by simulation and experimental results under different operating conditions. The highest conversion efficiency achieved by the prototype was $96.6 \%$ in the battery discharging mode with two input sources of $V_{\mathrm{in} 1}=36 \mathrm{~V}$ and $V_{\mathrm{in} 2}=48 \mathrm{~V}$.

\section{Topology and Operation Modes of the Proposed Power Converter}

The proposed converter topology was derived on the basis of a nonisolated MIMO boost converter [26]; the system structure of the proposed converter is shown in Figure 1. The proposed power converter receives the HEV electrical power from the FC and battery sources and converts it 
to a suitable high voltage, which is applied to a dc-microgrid so that dc home appliances can use the electricity directly. In Figure $1, R_{\mathrm{o} 1}-R_{\mathrm{o} 3}$ are the load resistances that represent the equivalent power feeding dc-microgrid. The four power switches $S_{\mathrm{c}}, S_{\mathrm{d}}, S_{\mathrm{b}}$, and $S_{\mathrm{o}}$ in the converter structure are the main active switches that control the power flow and output voltages of the converter. In the proposed converter, source $V_{\text {in1 }}$ can deliver power to source $V_{\text {in2 }}$ but not vice versa. In this study, the FC was used as a generating power source $\left(V_{\text {in1 }}\right)$, and the battery was used as a storage device $\left(V_{\text {in2 } 2}\right)$. On the basis of the utilization state of the battery, two power operating modes were defined and investigated for the proposed converter as follows.

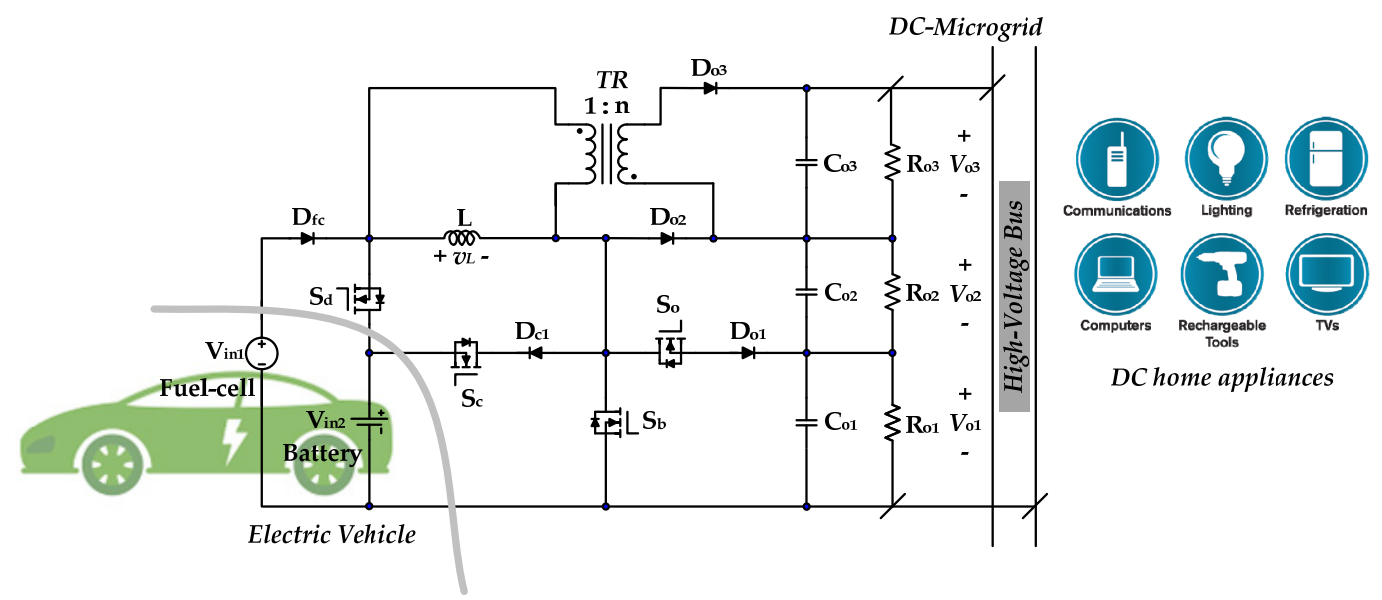

Figure 1. Proposed converter with two-input, three-output ports for a hybrid electric vehicle (HEV) connected to a dc-microgrid system.

\subsection{Battery Discharging Mode}

In the battery discharging mode, two input power sources $V_{\mathrm{in} 1}$ (FC) and $V_{\text {in2 }}$ (battery) supply energy to the loads. The switch $S_{\mathrm{c}}$ is turned off, and switches $S_{\mathrm{b}}, S_{\mathrm{d}}$, and $S_{\mathrm{o}}$ are actively switching. $S_{\mathrm{d}}$ is used to regulate the battery current to the desired value by controlling the inductor current. The total output voltage $\left(V_{\mathrm{o} 1}+V_{\mathrm{o} 2}+V_{\mathrm{o} 3}=V_{\mathrm{T}}\right)$ is regulated to the desired value by the duty cycle of the switch $S_{\mathrm{b}}$. Moreover, the output voltage $V_{\mathrm{o} 1}$ is controlled by $S_{\mathrm{o}}$. Because of the regulation of $V_{\mathrm{T}}$ and $V_{\mathrm{o} 1}$, the output voltages $V_{\mathrm{o} 2}$ and $V_{\mathrm{o} 3}$ are regulated. Figure 2 shows the gate signals of switches and voltage and current waveforms of the inductor.

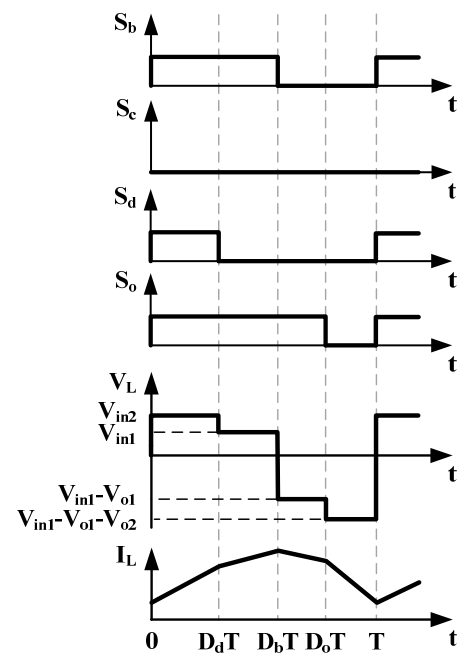

Figure 2. Steady-state waveforms of the proposed power converter in the battery discharging mode. 
According to the switch states, four operating modes exist in one switching period, as shown in Figure 3.

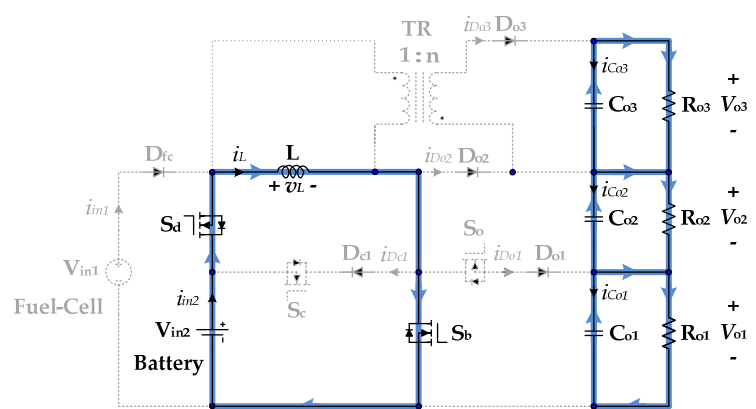

(a)

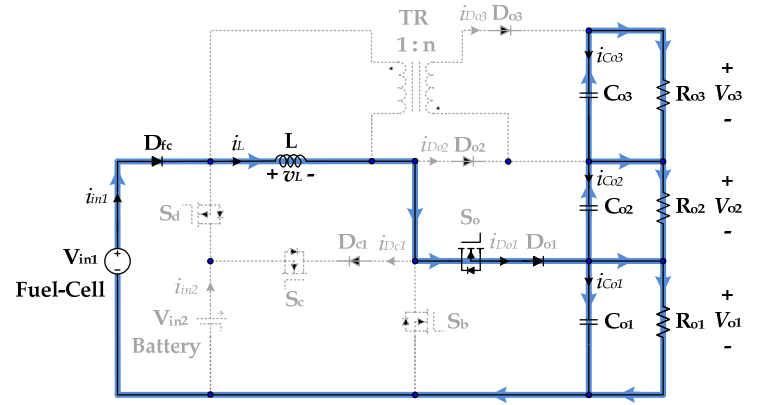

(c)

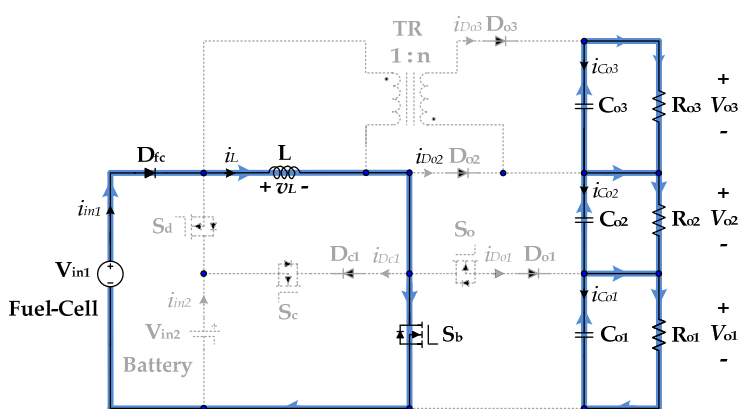

(b)

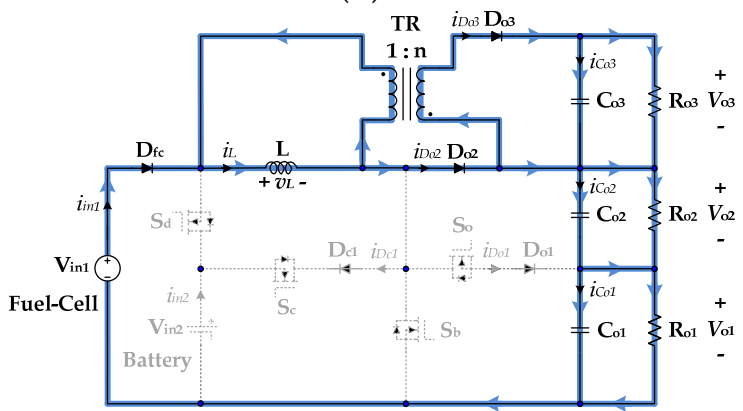

(d)

Figure 3. Equivalent circuits of the battery discharging mode: (a) State $1\left(0<t<D_{\mathrm{d}} T\right)$; (b) State $2\left(D_{\mathrm{d}} T\right.$ $\left.<t<D_{\mathrm{b}} T\right)$; (c) State $3\left(D_{\mathrm{b}} T<t<D_{\mathrm{o}} T\right)$; and (d) State $4\left(D_{\mathrm{o}} T<t<T\right)$.

State $1\left(0<t<D_{\mathrm{d}} T\right)$ : In this state, the switches $S_{\mathrm{b}}, S_{\mathrm{d}}$, and $S_{\mathrm{o}}$ are turned on. Because $S_{\mathrm{b}}$ is turned on, diodes $D_{\mathrm{o} 1}, D_{\mathrm{o} 2}$, and $D_{\mathrm{o} 3}$ are reverse-biased, and switch $S_{\mathrm{c}}$ is turned off. Moreover, because $S_{\mathrm{d}}$ is turned on and $V_{\mathrm{in} 1}<V_{\mathrm{in} 2}$, the diode $D_{\mathrm{fc}}$ is reverse-biased. Figure 3 a shows the equivalent circuit of the proposed converter in this state. $V_{\text {in2 }}$ charges the inductor $L$, and the inductor current increases linearly. Moreover, the capacitors $C_{01}-C_{03}$ are discharged and deliver their stored energy to the load resistances $R_{\mathrm{o} 1}-R_{\mathrm{o} 3}$. The inductor and capacitor equations in this state are as follows:

$$
\left\{\begin{array}{c}
L \frac{\mathrm{d} i_{\mathrm{L}}}{\mathrm{d} t}=v_{\mathrm{in} 2} \\
C_{\mathrm{o} 1} \frac{\mathrm{d} v_{\mathrm{o} 1}}{\mathrm{~d} t}=-\frac{v_{\mathrm{o} 1}}{R_{\mathrm{o} 1}} \\
C_{\mathrm{o} 2} \frac{\mathrm{d} v_{\mathrm{o} 2}}{\mathrm{~d} t}=-\frac{v_{\mathrm{o} 2}}{R_{\mathrm{o} 2}} \\
C_{\mathrm{o} 3} \frac{\mathrm{d} v_{\mathrm{o} 3}}{\mathrm{~d} t}=-\frac{v_{\mathrm{o} 3}}{R_{\mathrm{o} 3}}
\end{array}\right.
$$

State $2\left(D_{\mathrm{d}} T<t<D_{\mathrm{b}} T\right)$ : In this state, the switch $S_{\mathrm{b}}$ is turned on, switch $S_{\mathrm{d}}$ is turned off, and diodes $D_{\mathrm{o} 1}, D_{\mathrm{o} 2}$, and $D_{\mathrm{o} 3}$ are reverse-biased. $V_{\mathrm{in} 1}$ charges the inductor $L$, and the inductor current increases linearly. In addition, the capacitors $C_{01}-C_{03}$ are discharged and deliver their stored energy to 
the load resistances $R_{\mathrm{O} 1}-R_{\mathrm{o} 3}$. Figure $3 \mathrm{~b}$ shows the equivalent circuit of the proposed converter in this state. The inductor and capacitor equations in this state are as follows:

$$
\left\{\begin{aligned}
L \frac{\mathrm{d} i_{\mathrm{L}}}{\mathrm{d} t} & =v_{\mathrm{in} 1} \\
C_{\mathrm{o} 1} \frac{\mathrm{d} v_{\mathrm{o} 1}}{\mathrm{~d} t} & =-\frac{v_{\mathrm{o} 1}}{R_{\mathrm{o} 1}} \\
C_{\mathrm{o} 2} \frac{\mathrm{d} v_{\mathrm{O} 2}}{\mathrm{~d} t} & =-\frac{v_{\mathrm{O} 2}}{R_{\mathrm{o} 2}} \\
C_{\mathrm{o} 3} \frac{\mathrm{d} v_{\mathrm{o} 3}}{\mathrm{~d} t} & =-\frac{v_{\mathrm{O} 3}}{R_{\mathrm{o} 3}}
\end{aligned}\right.
$$

State $3\left(D_{\mathrm{b}} T<t<D_{\mathrm{o}} T\right)$ : In this state, the switches $S_{\mathrm{b}}$ and $S_{\mathrm{d}}$ are turned off, switch $S_{\mathrm{o}}$ is turned on, and diodes $D_{\mathrm{o} 2}$ and $D_{\mathrm{o} 3}$ are reverse-biased. The inductor $L$ is discharged and delivers the energy to the capacitor $C_{\mathrm{o} 1}$ and load resistance $R_{\mathrm{o} 1}$; the inductor current decreases linearly. The capacitor $C_{\mathrm{o} 1}$ is charged, and the capacitors $C_{\mathrm{o} 2}$ and $C_{\mathrm{o} 3}$ are discharged and deliver the stored energy to load resistances $R_{\mathrm{O} 2}$ and $R_{\mathrm{O} 3}$. Figure 3c shows the equivalent circuit of the proposed converter in this state. The energy storage element $L$ and $C_{01}-C_{03}$ equations in this state are as follows:

$$
\left\{\begin{array}{c}
L \frac{\mathrm{d} i_{\mathrm{L}}}{\mathrm{d} t}=v_{\mathrm{in} 1}-v_{\mathrm{o} 1} \\
C_{\mathrm{o} 1} \frac{\mathrm{d} v_{\mathrm{o} 1}}{\mathrm{~d} t}=i_{\mathrm{L}}-\frac{v_{\mathrm{o} 1}}{R_{\mathrm{o} 1}} \\
C_{\mathrm{o} 2} \frac{\mathrm{d} v_{\mathrm{O} 2}}{\mathrm{~d} t}=-\frac{v_{\mathrm{O} 2}}{R_{\mathrm{o} 2}} \\
C_{\mathrm{o} 3} \frac{\mathrm{d} v_{\mathrm{O} 3}}{\mathrm{~d} t}=-\frac{v_{\mathrm{o} 3}}{R_{\mathrm{o} 3}}
\end{array}\right.
$$

State $4\left(D_{\mathrm{o}} T<t<T\right)$ : In this state, all switches are turned off. The diode $D_{\mathrm{o} 1}$ is reverse-biased, and diodes $D_{\mathrm{o} 2}$ and $D_{\mathrm{o} 3}$ are forward-biased. The energy stored in the inductor $L$ is now partly discharged through the ideal transformer and the inductor delivers the stored energy to the capacitors $C_{\mathrm{o} 1}-C_{\mathrm{o} 3}$ and load resistances $R_{\mathrm{o} 1}-R_{\mathrm{o} 3}$. Figure $3 \mathrm{~d}$ shows the equivalent circuit of the proposed converter in this state. The inductor and capacitor equations in this state are as follows:

$$
\left\{\begin{array}{c}
L \frac{\mathrm{d} i_{\mathrm{L}}}{\mathrm{d} t}=v_{\mathrm{in} 1}-\left(v_{\mathrm{o} 1}+v_{\mathrm{o} 2}\right)=-\frac{v_{\mathrm{o} 3}}{n} \\
C_{\mathrm{o} 1} \frac{\mathrm{d} v_{\mathrm{o} 1}}{\mathrm{~d} t}=\alpha i_{\mathrm{L}}-\frac{v_{\mathrm{o} 1}}{R_{\mathrm{o} 1}} \\
C_{\mathrm{o} 2} \frac{\mathrm{d} v_{\mathrm{o} 2}}{\mathrm{~d} t}=\alpha i_{\mathrm{L}}-\frac{v_{\mathrm{o} 2}}{R_{\mathrm{o} 2}} \\
C_{\mathrm{o} 3} \frac{\mathrm{d} v_{\mathrm{o} 3}}{\mathrm{~d} t}=\frac{\beta i_{\mathrm{L}}}{n}-\frac{v_{\mathrm{o} 3}}{R_{\mathrm{o} 3}}
\end{array}\right.
$$

where $n$ represents the transformer turn ratio and $\alpha$ and $\beta$ are the ratios of the inductor current that contributes the energy to load resistances $R_{\mathrm{o} 2}$ and $R_{\mathrm{o} 3}$, respectively; that is $(\alpha+\beta=1)$.

\subsection{Battery Charging Mode}

In the battery charging mode, $V_{\text {in1 }}(\mathrm{FC})$ not only supplies loads but also supplies power to $V_{\text {in2 }}$ (battery). This condition occurs when the load power is low and the battery must be charged. In this operating mode, switches $S_{\mathrm{b}}, S_{\mathrm{c}}$, and $S_{\mathrm{o}}$ are actively switching and switch $S_{\mathrm{d}}$ is turned off. $S_{\mathrm{b}}$ is controlled to regulate total output voltage $\left(V_{\mathrm{o} 1}+V_{\mathrm{o} 2}+V_{\mathrm{o} 3}=V_{\mathrm{T}}\right)$ to the desired value. The battery charging current is regulated to the desired value by the duty cycle of $S_{c}$. Moreover, the output voltage $V_{\mathrm{o} 1}$ is controlled by $S_{\mathrm{o}}$. Because of the regulation of $V_{\mathrm{T}}$ and $V_{\mathrm{o} 1}$, the output voltages $V_{\mathrm{o} 2}$ and $V_{\mathrm{o} 3}$ are regulated. 
Figure 4 shows the gate signals of switches and voltage and current waveforms of the inductor. According to the switch states, four modes exist in one switching period, as shown in Figure 5.

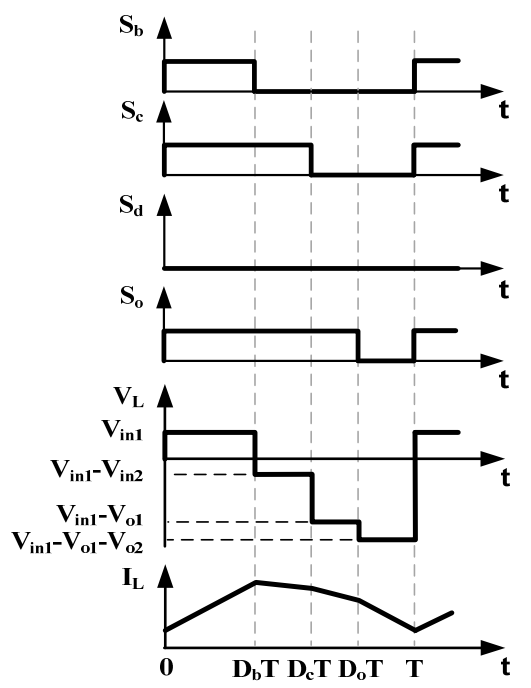

Figure 4. Steady-state waveforms of the proposed power converter in the battery charging mode.

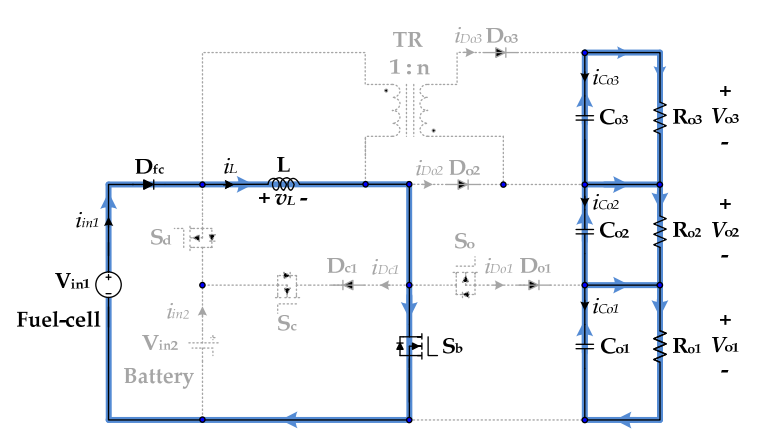

(a)

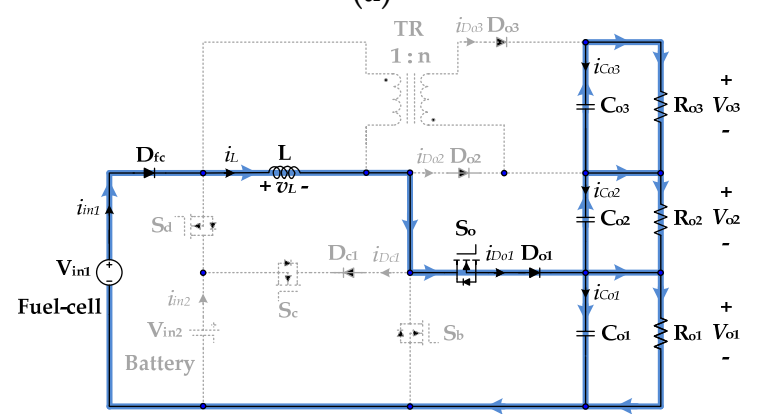

(c)

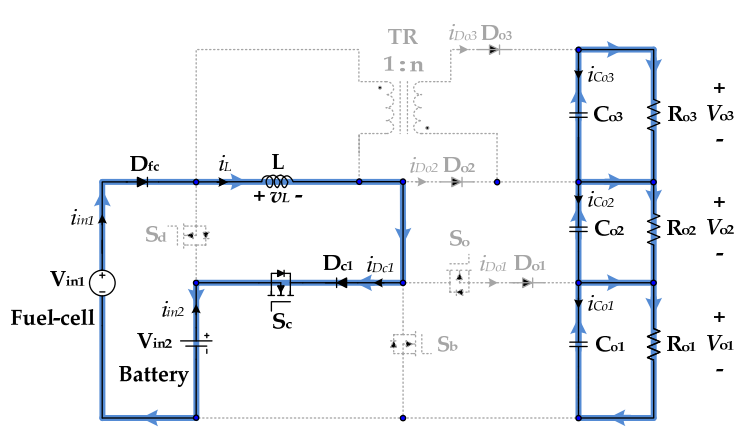

(b)

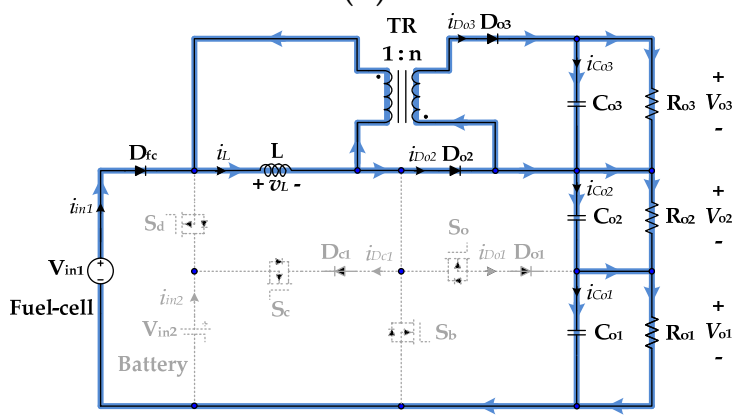

(d)

Figure 5. Equivalent circuits of the battery charging mode: (a) State $1\left(0<t<D_{\mathrm{b}} T\right)$; (b) State $2\left(D_{\mathrm{b}} T<t\right.$ $\left.<D_{\mathrm{c}} T\right)$; (c) State $3\left(D_{\mathrm{c}} T<t<D_{\mathrm{o}} T\right)$; and (d) State $4\left(D_{\mathrm{o}} T<t<T\right)$.

State $1\left(0<t<D_{\mathrm{b}} T\right)$ : In this state, switch $S_{\mathrm{d}}$ is turned off; switches $S_{\mathrm{b}}, S_{\mathrm{c}}$, and $S_{\mathrm{o}}$ are turned on; and diodes $D_{\mathrm{o} 1}-D_{\mathrm{o} 3}$ are reverse-biased. $V_{\mathrm{in} 1}$ charges the inductor $L$, and the inductor current increases linearly. Moreover, the capacitors $C_{\mathrm{o} 1}-C_{\mathrm{o} 3}$ are discharged and deliver their stored energy to the load resistances $R_{\mathrm{O} 1}-R_{\mathrm{O} 3}$. Figure 5a shows the equivalent circuit of the proposed converter in this state. The inductor and capacitor equations in this state are as follows: 


$$
\left\{\begin{array}{c}
L \frac{\mathrm{d} i_{\mathrm{L}}}{\mathrm{d} t}=v_{\mathrm{in} 1} \\
C_{\mathrm{o} 1} \frac{\mathrm{d} v_{\mathrm{o} 1}}{\mathrm{~d} t}=-\frac{v_{\mathrm{o} 1}}{R_{\mathrm{o} 1}} \\
C_{\mathrm{o} 2} \frac{\mathrm{d} v_{\mathrm{o} 2}}{\mathrm{~d} t}=-\frac{v_{\mathrm{o} 2}}{R_{\mathrm{o} 2}} \\
C_{\mathrm{o} 3} \frac{\mathrm{d} v_{\mathrm{o} 3}}{\mathrm{~d} t}=-\frac{v_{\mathrm{o} 3}}{R_{\mathrm{o} 3}}
\end{array}\right.
$$

State $2\left(D_{\mathrm{b}} T<t<D_{\mathrm{c}} T\right)$ : In this state, the switches $S_{\mathrm{c}}$ and $S_{\mathrm{o}}$ are turned on, switches $S_{\mathrm{d}}$ and $S_{\mathrm{b}}$ are turned off, and diodes $D_{\mathrm{o} 1}-D_{\mathrm{o} 3}$ are reverse-biased. Because $V_{\mathrm{in} 1}<V_{\mathrm{in} 2}$ in this state, during this period, the inductor current decreases linearly and the inductor delivers the energy to the battery $\left(V_{\mathrm{in} 2}\right)$. Moreover, the capacitors $C_{\mathrm{o} 1}-C_{\mathrm{O} 3}$ are discharged and deliver their stored energy to the load resistances $R_{\mathrm{o} 1}-R_{\mathrm{O} 3}$. Figure $5 \mathrm{~b}$ shows the equivalent circuit of the proposed converter in this state. The inductor and capacitor equations in this mode are as follows:

$$
\left\{\begin{array}{l}
L \frac{\mathrm{d} i_{\mathrm{L}}}{\mathrm{d} t}=v_{\mathrm{in} 1}-v_{\mathrm{in} 2} \\
C_{\mathrm{o} 1} \frac{\mathrm{d} v_{\mathrm{o} 1}}{\mathrm{~d} t}=-\frac{v_{\mathrm{o} 1}}{R_{\mathrm{o} 1}} \\
C_{\mathrm{o} 2} \frac{\mathrm{d} v_{\mathrm{o} 2}}{\mathrm{~d} t}=-\frac{v_{\mathrm{o} 2}}{R_{\mathrm{o} 2}} \\
C_{\mathrm{o} 3} \frac{\mathrm{d} v_{\mathrm{o} 3}}{\mathrm{~d} t}=-\frac{v_{\mathrm{o} 3}}{R_{\mathrm{o} 3}}
\end{array}\right.
$$

State $3\left(D_{\mathrm{c}} T<t<D_{\mathrm{o}} T\right)$ : In this state, switches $S_{\mathrm{d}}, S_{\mathrm{b}}$, and $S_{\mathrm{c}}$ are turned off; switch $S_{\mathrm{o}}$ is turned on; and diodes $D_{\mathrm{o} 2}$ and $D_{\mathrm{o} 3}$ are reverse-biased. The inductor $L$ is discharged and delivers the energy to the capacitor $C_{\mathrm{o} 1}$ and load resistance $R_{\mathrm{o} 1}$; the inductor current decreases linearly. The capacitor $C_{\mathrm{o} 1}$ is charged, and the capacitors $C_{\mathrm{o} 2}$ and $C_{\mathrm{o} 3}$ are discharged and deliver the stored energy to the load resistances $R_{\mathrm{o} 2}-R_{\mathrm{o} 3}$. Figure $5 \mathrm{c}$ shows the equivalent circuit of the proposed converter in this state. The energy storage element $L$ and $C_{\mathrm{o} 1}-C_{\mathrm{o} 3}$ equations in this state are as follows:

$$
\left\{\begin{array}{c}
L \frac{\mathrm{d} i_{\mathrm{L}}}{\mathrm{d} t}=v_{\mathrm{in} 1}-v_{\mathrm{o} 1} \\
C_{\mathrm{o} 1} \frac{\mathrm{d} v_{\mathrm{o} 1}}{\mathrm{~d} t}=i_{L}-\frac{v_{\mathrm{o} 1}}{R_{\mathrm{o} 1}} \\
C_{\mathrm{o} 2} \frac{\mathrm{d} v_{\mathrm{o} 2}}{\mathrm{~d} t}=-\frac{v_{\mathrm{o} 2}}{R_{\mathrm{o} 2}} \\
C_{\mathrm{o} 3} \frac{\mathrm{d} v_{\mathrm{o} 3}}{\mathrm{~d} t}=-\frac{v_{\mathrm{o} 3}}{R_{\mathrm{o} 3}}
\end{array}\right.
$$

State $4\left(D_{\mathrm{o}} T<t<T\right)$ : In this state, all the switches are turned off. The diode $D_{\mathrm{o} 1}$ is reverse-biased, and diodes $D_{\mathrm{o} 2}$ and $D_{\mathrm{o} 3}$ are forward-biased. The inductor $L$ is discharged, and the energy stored in $L$ is now partly discharged through the ideal transformer to deliver the stored energy to the capacitors $C_{\mathrm{o} 1}-C_{\mathrm{o} 3}$ and load resistances $R_{\mathrm{o} 1}-R_{\mathrm{o} 3}$. Figure $5 \mathrm{~d}$ shows the equivalent circuit of the proposed converter in this state. The inductor and capacitor equations are as follows:

$$
\left\{\begin{array}{c}
L \frac{\mathrm{d} i_{\mathrm{L}}}{\mathrm{d} t}=v_{\mathrm{in} 1}-\left(v_{\mathrm{o} 1}+v_{\mathrm{o} 2}\right)=-\frac{v_{\mathrm{o} 3}}{n} \\
C_{\mathrm{o} 1} \frac{\mathrm{d} v_{\mathrm{o} 1}}{\mathrm{~d} t}=\alpha i_{\mathrm{L}}-\frac{v_{\mathrm{o} 1}}{R_{\mathrm{o} 1}} \\
C_{\mathrm{o} 2} \frac{\mathrm{d} v_{\mathrm{o} 2}}{\mathrm{~d} t}=\alpha i_{\mathrm{L}}-\frac{v_{\mathrm{o} 2}}{R_{\mathrm{o} 2}} \\
C_{\mathrm{o} 3} \frac{\mathrm{d} v_{\mathrm{o} 3}}{\mathrm{~d} t}=\frac{\beta i_{\mathrm{L}}}{n}-\frac{v_{\mathrm{o} 3}}{R_{\mathrm{o} 3}}
\end{array}\right.
$$




\section{Steady-State Analysis}

In the battery discharging mode, the energy of the two inputs can be controlled by tuning the duty cycle $D_{\mathrm{d}}$ of the switch $S_{\mathrm{d}}$. Moreover, the total output voltage $\left(V_{\mathrm{o} 1}+V_{\mathrm{o} 2}+V_{\mathrm{o} 3}=V_{\mathrm{T}}\right)$ can be regulated to the desired value by tuning the duty cycles $D_{\mathrm{b}}$ and $D_{\mathrm{o}}$ of the switches $S_{\mathrm{b}}$ and $S_{\mathrm{o}}$, respectively. In the battery charging mode, the energy of the input power source $V_{\text {in1 }}$ can be controlled to charge the battery by tuning the duty cycles $D_{\mathrm{b}}$ and $D_{\mathrm{c}}$ of the switches $S_{\mathrm{b}}$ and $S_{\mathrm{c}}$, respectively. Moreover, the total output voltage $V_{\mathrm{T}}$ can be regulated to the desired value by tuning the duty cycles $D_{\mathrm{c}}$ and $D_{\mathrm{o}}$ of the switches $S_{\mathrm{c}}$ and $S_{\mathrm{o}}$, respectively.

According to the voltage-second balance principle and Equations (1)-(4):

$$
\begin{gathered}
V_{\mathrm{in} 1}\left(1-D_{\mathrm{d}}\right)+V_{\mathrm{in} 2} D_{\mathrm{d}}=V_{\mathrm{o} 1}\left(1-D_{\mathrm{b}}\right)+V_{\mathrm{o} 2}\left(1-D_{\mathrm{o}}\right) \\
V_{\mathrm{in} 1}\left(D_{\mathrm{o}}-D_{\mathrm{d}}\right)+V_{\mathrm{in} 2} D_{\mathrm{d}}=V_{\mathrm{o} 1}\left(D_{\mathrm{o}}-D_{\mathrm{b}}\right)+\frac{V_{\mathrm{o} 3}}{n}\left(1-D_{\mathrm{o}}\right)
\end{gathered}
$$

Similarly, according to Equations (5)-(8):

$$
\begin{gathered}
V_{\mathrm{in} 1}+V_{\mathrm{in} 2}\left(D_{\mathrm{b}}-D_{\mathrm{c}}\right)=V_{\mathrm{o} 1}\left(1-D_{\mathrm{c}}\right)+V_{\mathrm{o} 2}\left(1-D_{\mathrm{o}}\right) \\
V_{\mathrm{in} 1} D_{\mathrm{o}}+V_{\mathrm{in} 2}\left(D_{\mathrm{b}}-D_{\mathrm{c}}\right)=V_{\mathrm{o} 1}\left(D_{\mathrm{o}}-D_{\mathrm{c}}\right)+\frac{V_{\mathrm{o} 3}}{n}\left(1-D_{\mathrm{o}}\right)
\end{gathered}
$$

According to the equivalent circuits (State 4 ) of the battery charging and discharging modes, the inductor current delivers the stored energy to load resistances $R_{\mathrm{o} 2}$ and $R_{\mathrm{O} 3}$, and the corresponding distributed currents for $R_{\mathrm{o} 2}$ and $R_{\mathrm{O} 3}$ can be expressed as follows:

$$
\begin{aligned}
& I_{D \mathrm{o} 2}=\frac{V_{\mathrm{o} 2}}{R_{2}}=\left(1-D_{\mathrm{o}}\right) \alpha I_{\mathrm{L}} \\
& I_{D \mathrm{o} 3}=\frac{V_{\mathrm{o} 3}}{R_{3}}=\left(1-D_{\mathrm{o}}\right) \frac{\beta}{n} I_{\mathrm{L}}
\end{aligned}
$$

According to Equations (13) and (14):

$$
\frac{\alpha}{\beta}=n \frac{V_{\mathrm{o} 2}}{V_{\mathrm{o} 3}} \frac{R_{3}}{R_{2}}
$$

In summary, the values of the switch duty cycles of the discharging and charging modes are obtained using steady-state equations, which are expressed by Equations (16) and (17), respectively.

$$
\begin{aligned}
& {\left[\begin{array}{ccc}
V_{\mathrm{o} 1} & V_{\mathrm{in} 2}-V_{\mathrm{in} 1} & V_{\mathrm{o} 2} \\
R_{\mathrm{o} 1} I_{\mathrm{b}} & V_{\mathrm{o} 1} & R_{\mathrm{o} 1} I_{\mathrm{b}}(\alpha-1) \\
0 & V_{\mathrm{o} 2} & \alpha R_{\mathrm{o} 2} I_{\mathrm{b}} \\
0 & V_{\mathrm{o} 3} & \frac{\beta}{N} R_{\mathrm{o} 3} I_{\mathrm{b}}
\end{array}\right]\left[\begin{array}{c}
D_{\mathrm{b}} \\
D_{\mathrm{d}} \\
D_{\mathrm{o}}
\end{array}\right]=\left[\begin{array}{c}
V_{\mathrm{o} 1}+V_{\mathrm{o} 2}-V_{\mathrm{in} 1} \\
\alpha R_{\mathrm{o} 1} I_{\mathrm{b}} \\
\alpha R_{\mathrm{o} 2} I_{\mathrm{b}} \\
\frac{\beta}{N} R_{\mathrm{o} 3} I_{\mathrm{b}}
\end{array}\right]} \\
& {\left[\begin{array}{ccc}
V_{\mathrm{in} 2} & V_{\mathrm{o} 1}-V_{\mathrm{in} 2} & V_{\mathrm{o} 2} \\
R_{\mathrm{o} 1} I_{\mathrm{b}} & V_{\mathrm{o} 1} & R_{\mathrm{o} 1} I_{\mathrm{b}}(\alpha-1) \\
0 & V_{\mathrm{o} 2} & \alpha R_{\mathrm{o} 2} I_{\mathrm{b}} \\
0 & V_{\mathrm{o} 3} & \frac{\beta}{N} R_{\mathrm{o} 3} I_{b}
\end{array}\right]\left[\begin{array}{c}
D_{\mathrm{b}} \\
D_{\mathrm{c}} \\
D_{\mathrm{o}}
\end{array}\right]=\left[\begin{array}{c}
V_{\mathrm{o} 1}+V_{\mathrm{o} 2}-V_{\mathrm{in} 1} \\
\alpha R_{\mathrm{o} 1} I_{\mathrm{b}} \\
\alpha R_{\mathrm{o} 2} I_{\mathrm{b}} \\
\frac{\beta}{N} R_{\mathrm{o} 3} I_{\mathrm{b}}
\end{array}\right]}
\end{aligned}
$$

\section{Simulation and Experimental Results}

To verify the performance of the proposed converter, experiments were conducted using a 300-W circuit prototype in battery discharging and charging modes. The corresponding simulation results 
were also made utilizing the PSIM simulation software [27]. The parameters are listed in Table 1. The input voltage sources were $V_{\mathrm{in} 1}=36 \mathrm{~V}$, and $V_{\mathrm{in} 2}=48 \mathrm{~V}$. The total output voltage was regulated as $V_{T-r e f}=V_{o 1-r e f}+V_{o 2-r e f}+V_{o 3-r e f}=300 \mathrm{~V} \pm 10 \%$ (i.e., 270-330 V), and the voltage regulation ranges of the three-output terminals were set to $V_{o 1-r e f}=V_{o 2-r e f}=80 \pm 10 \%$ (i.e., $72-88 \mathrm{~V}$ ) and $V_{o 3-r e f}=140$ $\pm 10 \%$ (i.e., $126-154 \mathrm{~V}$ ). Moreover, the average battery currents were regulated as $I_{\mathrm{b}(\mathrm{avg})}=1.4 \mathrm{~A}$ and $I_{\mathrm{b}(\mathrm{avg})}=-0.85 \mathrm{~A}$ for the battery discharging and charging modes, respectively. The load resistances $R_{\mathrm{o} 1}=150 \Omega, R_{\mathrm{o} 2}=75 \Omega$, and $R_{\mathrm{o} 3}=75 \Omega$ were used for the battery discharging and charging modes, which are described in Sections 4.1 and 4.2 respectively.

Table 1. Specifications/component parameters. FC: fuel cell.

\begin{tabular}{cccc}
\hline \multicolumn{2}{c}{ Specifications } & \multicolumn{2}{c}{ Component Parameters } \\
\hline$V_{\text {in1 }}(\mathrm{FC})$ & $36 \mathrm{~V}$ & Transformer/magnetizing inductors & TR: EE55/55; $L: 250 \mu \mathrm{H}, n: 0.5$ \\
$V_{\text {in2 }}$ (battery) & $48 \mathrm{~V}$ & Capacitors & $C_{\mathrm{o} 1}-C_{\mathrm{o} 3}: 2 \mathrm{pcs} 470 \mu \mathrm{F} / 450 \mathrm{~V}$ in parallel \\
Output power & $P_{\mathrm{o}}: 300 \mathrm{~W}$ & Active switches & $S_{\mathrm{d}}, S_{\mathrm{o}}:$ FDA59N30; $S_{\mathrm{c}}, S_{\mathrm{b}}:$ FCH043N60 \\
Switching frequency & $f_{\mathrm{s}}: 20 \mathrm{kHz}$ & Diodes & F15S60S \\
\hline
\end{tabular}

\subsection{Battery Discharging Mode}

In the battery discharging mode, two input power sources $V_{\mathrm{in} 1}(\mathrm{FC})$ and $V_{\mathrm{in} 2}$ (battery) supply the energy to the loads. Figure 6 shows the measured waveforms of the switch gate signals and the voltage and current waveforms of the inductor. As shown in this figure, the switch $S_{\mathrm{c}}$ is turned off, and the switches $S_{\mathrm{b}}, S_{\mathrm{d}}$, and $S_{\mathrm{o}}$ are actively controlled. To control the output voltage, the duty cycles $D_{\mathrm{b}}$ and $D_{\mathrm{o}}$ are tuned first, and by tuning the duty cycle $D_{\mathrm{d}}$ to a higher value, the total output voltage $V_{\mathrm{T}}$ is higher, and vice versa. As shown in Figure 7, the regulated average battery current $I_{\mathrm{b}(\mathrm{avg})}=1.42 \mathrm{~A}$ and average inductor current $I_{\mathrm{L}(\mathrm{avg})}=4.78 \mathrm{~A}$ can be obtained. Notably, the battery current in this mode has a positive value, which implies that the battery has been discharged. Figure 8 shows both simulation and experimental results of the switch voltages in the battery discharging mode. The maximum voltage stresses of the power switches $S_{\mathrm{b}}, S_{\mathrm{d}}$, and $S_{\mathrm{o}}$ are $218 \mathrm{~V}, 13 \mathrm{~V}$, and $76 \mathrm{~V}$, respectively, which are in close agreement with the corresponding simulation results. All the voltage stresses are lower than the output voltage, and this result enables the adoption of lower voltage rating devices for reducing conduction and switching losses.

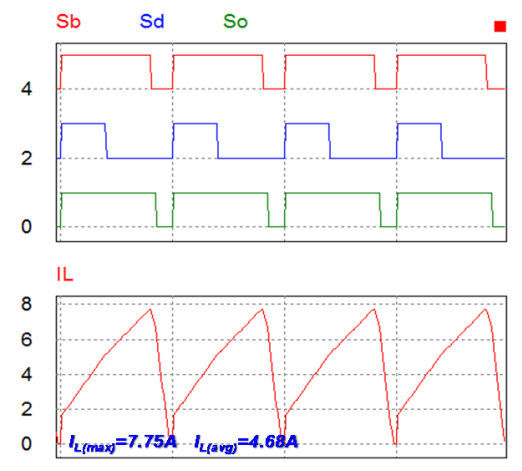

(a)

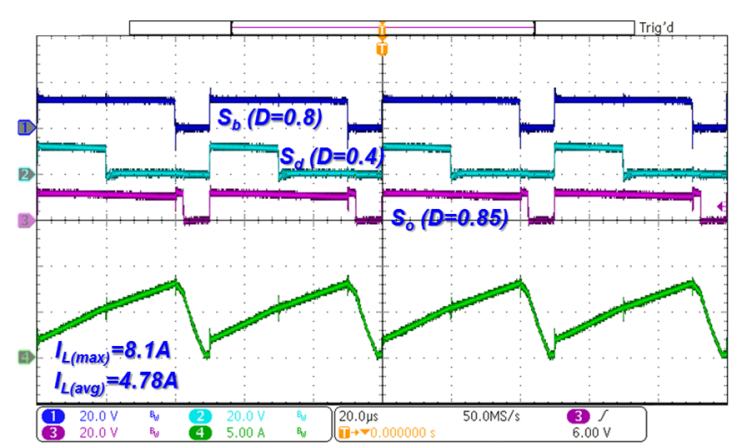

(b)

Figure 6. Gate driving signal and inductor current waveforms in the battery discharging mode: (a) by simulation; and (b) by measurement. 


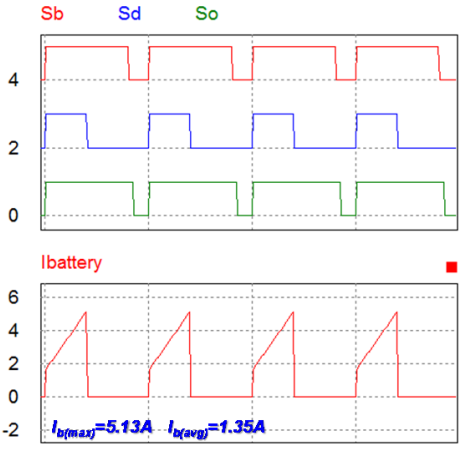

(a)

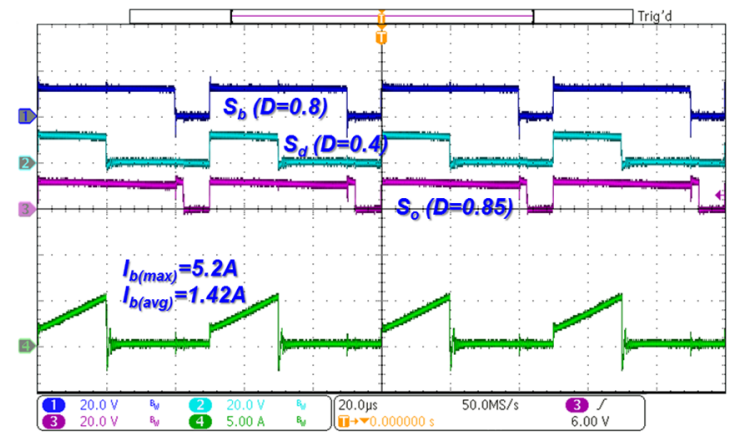

(b)

Figure 7. Gate driving signal and battery current waveforms in the battery discharging mode: (a) by simulation; and (b) by measurement.

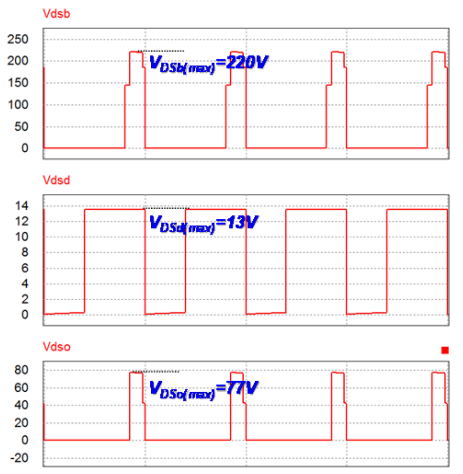

(a)

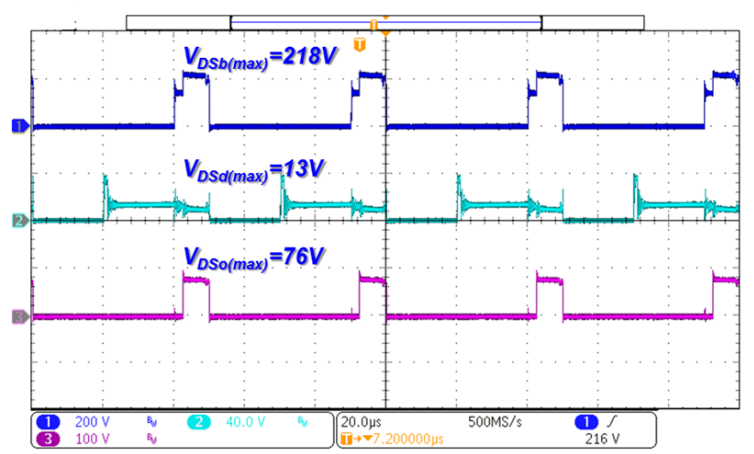

(b)

Figure 8. Switch voltage waveforms in the battery discharging mode: (a) by simulation; and (b) by measurement.

Figure 9 shows the measured waveforms of the diode voltages in the battery discharging mode; the maximum voltage stresses of the diodes $D_{\mathrm{o} 1}, D_{\mathrm{o} 2}$, and $D_{\mathrm{o} 3}$ are approximately $130 \mathrm{~V}, 204 \mathrm{~V}$, and $114 \mathrm{~V}$, respectively. As shown in Figure 9, both simulation and experimental results are consistent. As shown in Figure 10, the desired values of the output voltages are $V_{\mathrm{o} 1}=140 \mathrm{~V}, V_{\mathrm{o} 2}=85 \mathrm{~V}, V_{\mathrm{o} 3}=74 \mathrm{~V}$, and the total output voltage $V_{\mathrm{T}}=299 \mathrm{~V}$. The experimental results are consistent with the circuit simulation results.

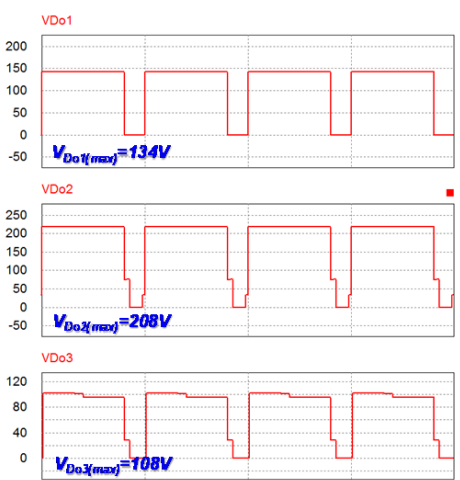

(a)

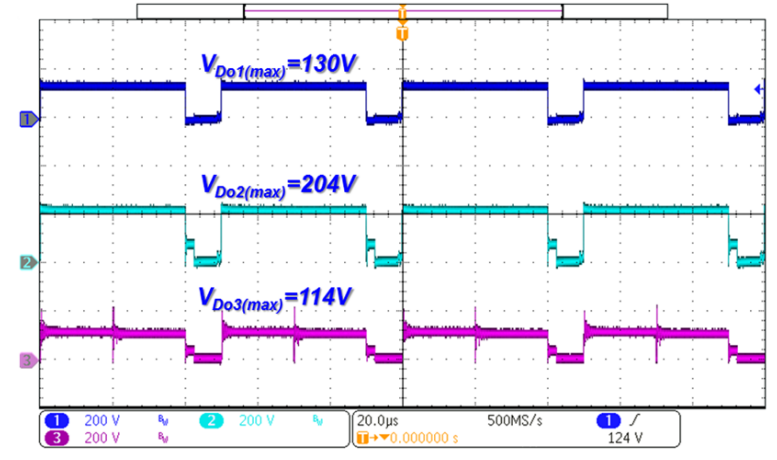

(b)

Figure 9. Diode voltage waveforms in the battery discharging mode: (a) by simulation; and (b) by measurement. 


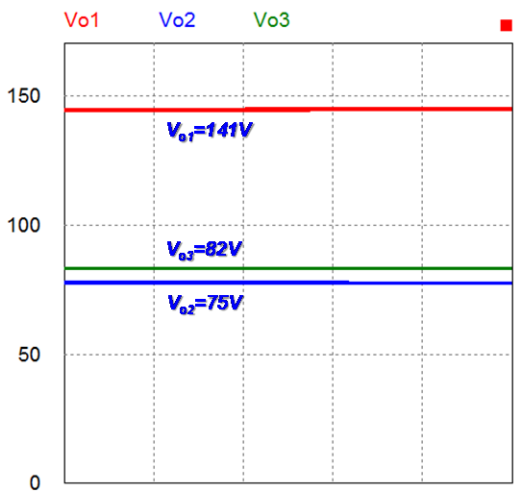

(a)

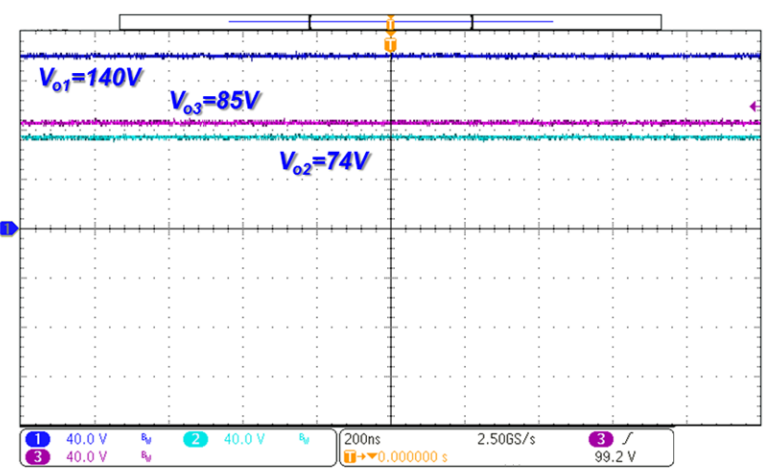

(b)

Figure 10. Output voltage waveforms in the battery discharging mode: (a) by simulation; and (b) by measurement.

\subsection{Battery Charging Mode}

In the battery charging mode, $V_{\text {in1 }}$ (FC) not only supplies loads but also delivers power to $V_{\text {in2 }}$ (battery). This condition occurs when the load power is low and the battery requires to be charged. Figure 11 shows the measured waveforms of the switch gate signals, and voltage and current waveforms of the inductor. As shown in this figure, the switch $S_{\mathrm{d}}$ is turned off, and the switches $S_{\mathrm{b}}, S_{\mathrm{c}}$, and $S_{\mathrm{o}}$ are actively controlled. As shown in Figure 12, the regulated average battery current $I_{\mathrm{b}(\mathrm{avg})}=-0.85 \mathrm{~A}$ and inductor current $I_{\mathrm{L}(\mathrm{avg})}=6.6 \mathrm{~A}$ are obtained. Notably, the battery current in this mode has a negative value, which implies that the battery has been charged. Figure 13 shows both simulation and experimental results of the switch voltages in the battery charging mode. The maximum voltage stresses of the power switches $S_{\mathrm{b}}, S_{\mathrm{c}}$, and $S_{\mathrm{o}}$ are $212 \mathrm{~V}, 176 \mathrm{~V}$, and $72 \mathrm{~V}$, respectively, which are in close agreement with the corresponding simulation results. Figure 14 shows the measured waveforms of the diode voltages in the battery charging mode; the maximum voltage stresses of the diodes $D_{\mathrm{o} 1}, D_{\mathrm{o} 2}$, and $D_{\mathrm{o} 3}$ are approximately $140 \mathrm{~V}, 216 \mathrm{~V}$, and $98 \mathrm{~V}$, respectively. Both the simulation and experimental results are in close agreement as well. As shown in Figure 15, the three-output voltages are $V_{\mathrm{o} 1}=142 \mathrm{~V}, V_{\mathrm{o} 2}=80 \mathrm{~V}, V_{\mathrm{o} 3}=70 \mathrm{~V}$, and the total output $V_{\mathrm{T}}=292 \mathrm{~V}$. These results are in the voltage regulation range as expected.

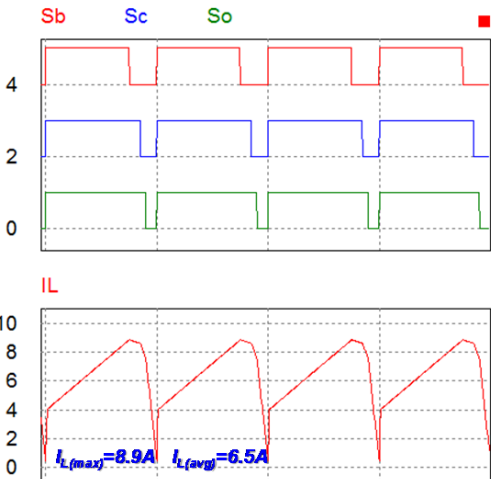

(a)

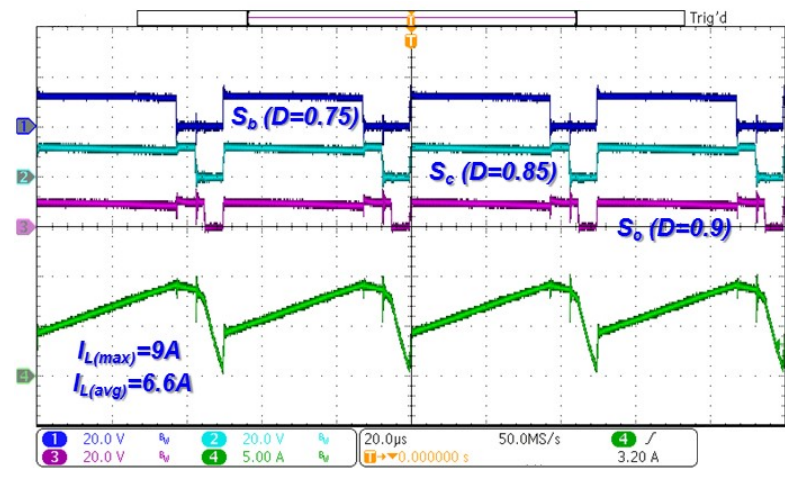

(b)

Figure 11. Gate driving signal and inductor current waveforms in the battery charging mode: (a) by simulation; and (b) by measurement. 


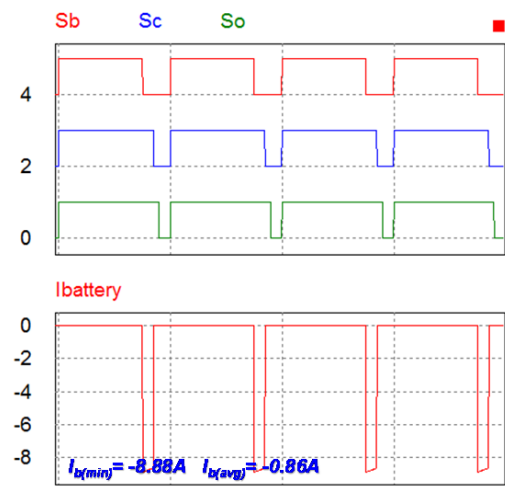

(a)

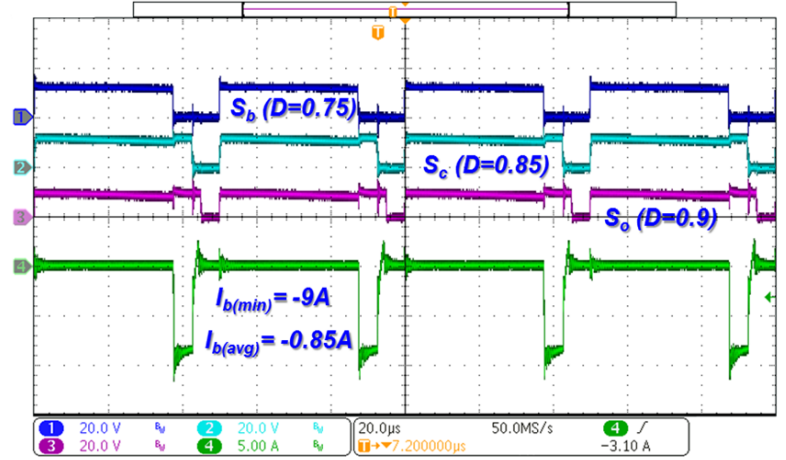

(b)

Figure 12. Gate driving signal and battery current waveforms in the battery charging mode: (a) by simulation; and (b) by measurement.

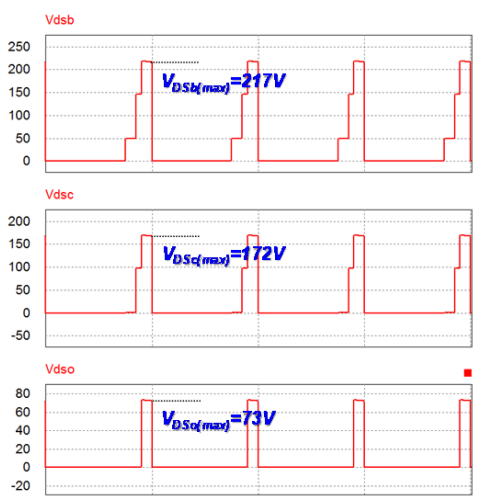

(a)

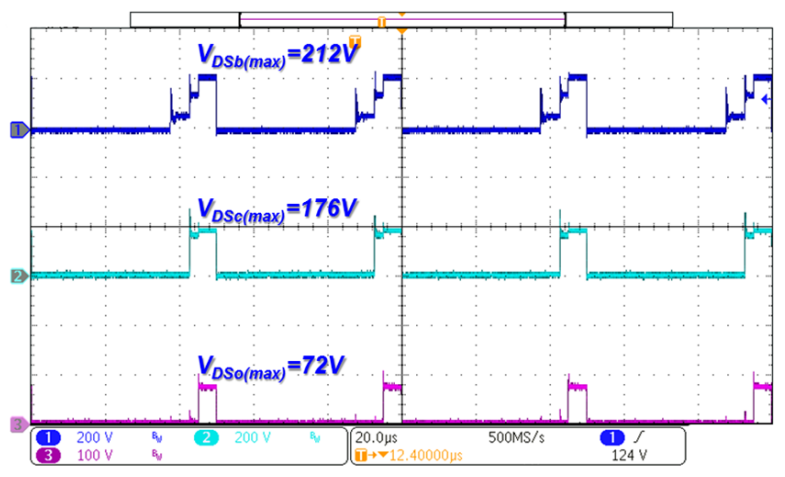

(b)

Figure 13. Switch voltage waveforms in the battery charging mode: (a) by simulation; and (b) by measurement.

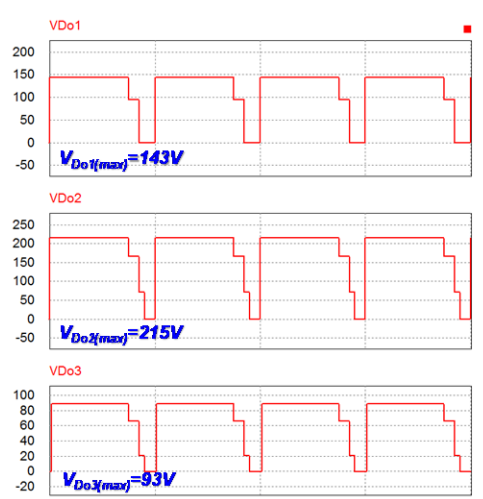

(a)

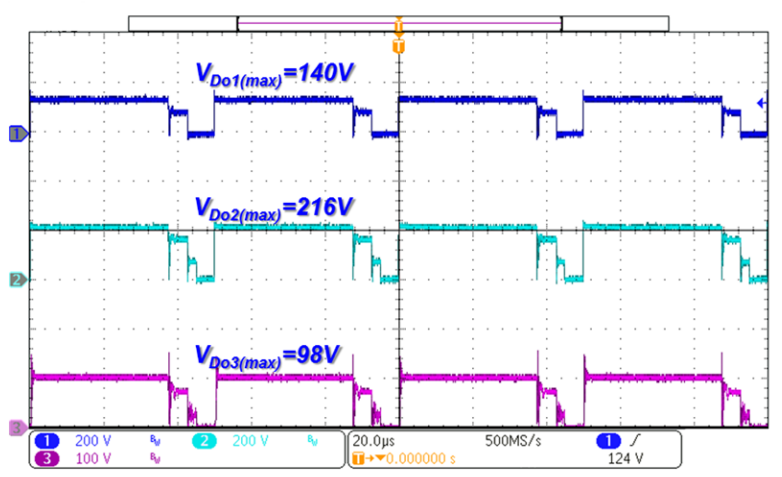

(b)

Figure 14. Diode voltage waveforms in the battery charging mode: (a) by simulation; and (b) by measurement. 


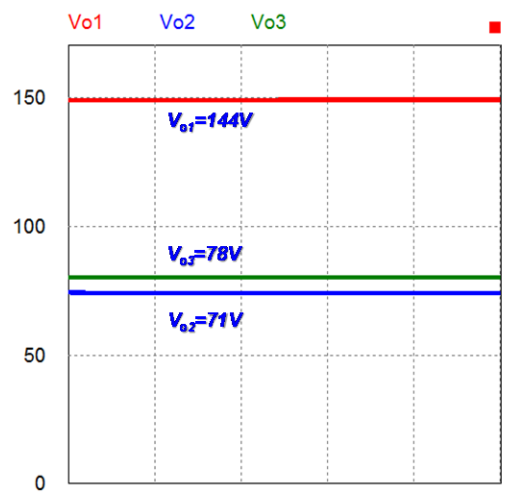

(a)

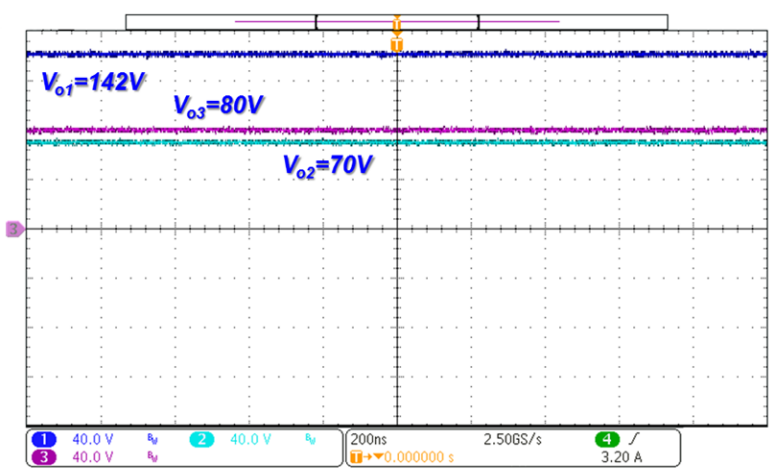

(b)

Figure 15. Output voltage waveforms in the battery charging mode: (a) by simulation; and (b) by measurement.

Figure 16 shows the measured conversion efficiency for different load conditions in the battery discharging mode. The conversion efficiency was measured using a digital power meter (Yokogawa-WT310, Tokyo, Japan). As shown in Figure 16, the measured highest conversion efficiency was as high as $96.6 \%$ at half-load output. In this condition, the load resistances are set as $R_{\mathrm{o} 1}=230 \Omega$, $R_{\mathrm{o} 2}=115 \Omega$, and $R_{\mathrm{o} 3}=660 \Omega$. Figure 17 shows the image of the realized prototype for reference.

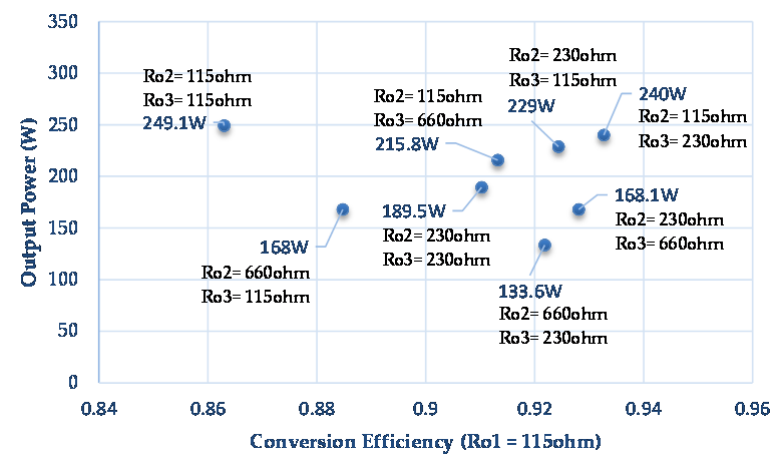

(a)

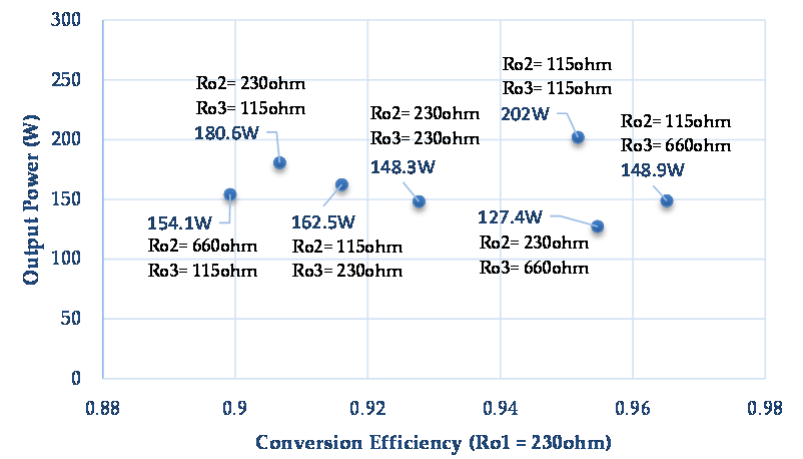

(b)

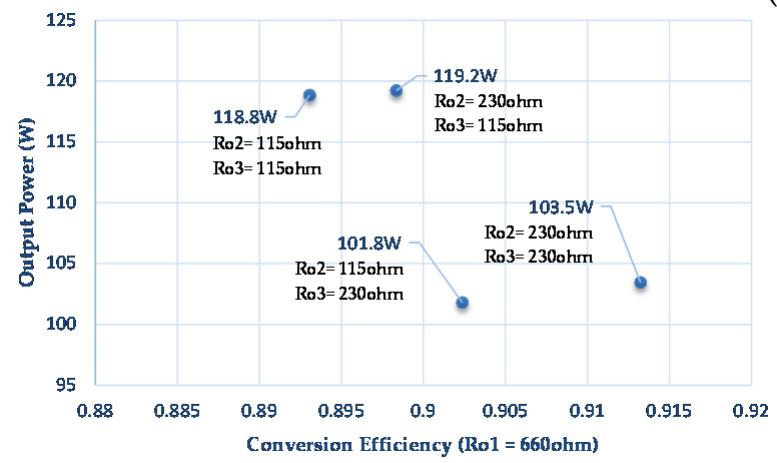

(c)

Figure 16. Measured conversion efficiency under different load conditions in the battery discharging mode: (a) $R_{\mathrm{o} 1}=115 \Omega$; (b) $R_{\mathrm{o} 1}=230 \Omega$; and (c) $R_{\mathrm{o} 1}=660 \Omega$ conditions. 


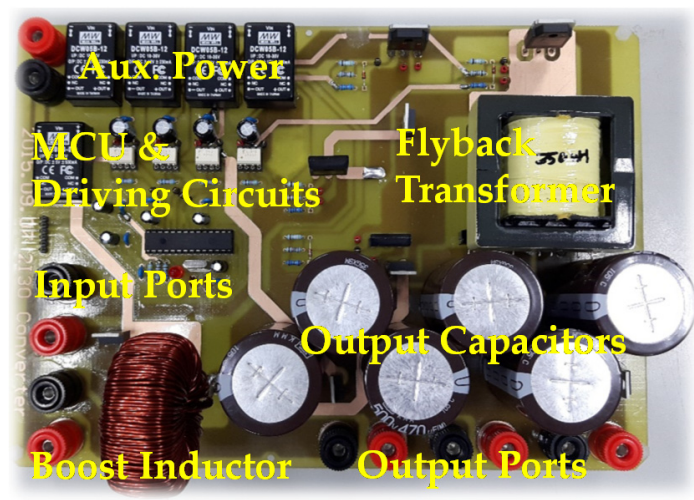

Figure 17. Realized converter prototype.

\section{Conclusions}

This paper proposed a high-gain three-port power converter with stacked output and simple configuration. The proposed converter receives the HEV electrical power from FC and battery sources and converts it to a suitable high voltage, which is applied to a dc-microgrid so that dc home appliances can use the electricity directly. The circuit operating principles and steady-state analysis of the proposed converter in battery discharging and charging modes were presented. The validity of the proposed power converter and its performance were verified through simulation and experimental results. The charging or discharging of the battery storage device can be controlled effectively using the FC source. Moreover, the measured highest conversion efficiency of the constructed prototype was as high as $96.6 \%$ in the battery discharging mode at two input sources of $V_{\text {in1 }}=36 \mathrm{~V}$ and $V_{\text {in2 }}=48 \mathrm{~V}$.

Acknowledgments: This research is sponsored by the Ministry of Science and Technology, Taiwan, under contracts 104-2221-E-027-125, 104-2623-E-027-005-ET, and 104-2622-E-027-023-CC3. The authors would like to thank their student, Yi-Yi Lin, for his help in the experiment, and Yuan-Chih Lin for his suggestions for this research.

Author Contributions: Ching-Ming Lai designed the study, analyzed data, and wrote the manuscript; Ming-Ji Yang gave conceptual advice.

Conflicts of Interest: The authors declare no conflict of interest.

\section{References}

1. Thounthong, P.; Chunkag, V.; Sethakul, P.; Davat, B.; Hinaje, M. Comparative study of fuel-cell vehicle hybridization with battery or supercapacitor storage device. IEEE Trans. Veh. Technol. 2009, 58, 3892-3905. [CrossRef]

2. Ehsani, M.; Gao, Y.; Emadi, A. Modern Electric, Hybrid Electric and Fuel Cell Vehicle Fundamentals, Theory and Design, 2nd ed.; CRC Press: Boca Raton, FL, USA, 2010.

3. Yilmaz, M.; Krein, P.T. Review of the impact of vehicle-to-grid technologies on distribution systems and utility interfaces. IEEE Trans. Power Electron. 2013, 28, 5673-5689. [CrossRef]

4. Farhangi, B.; Toliyat, H.A.; Balaster, A. High Impedance Grounding for Onboard Plug-in Hybrid Electric Vehicle Chargers. In Proceedings of the 2013 Fourth International Conference on Power Engineering, Energy and Electrical Drives (POWERENG), Istanbul, Turkey, 13-17 May 2013; pp. 609-613.

5. Lai, C.M.; Lin, Y.C.; Lee, D.S. Study and implementation of a two-phase interleaved bidirectional DC/DC converter for vehicle and dc-microgrid systems. Energies 2015, 8, 9969-9991. [CrossRef]

6. Thounthong, P.; Pierfederici, S.; Davat, B. Analysis of differential flatness-based control for fuel cell hybrid power source. IEEE Trans. Energy Convers. 2010, 25, 909-920. [CrossRef]

7. Bambang, R.T.; Rohman, A.S.; Dronkers, C.J.; Ortega, R.; Sasongko, A. Energy management of fuel cell/battery/supercapacitor hybrid power sources using model predictive control. IEEE Trans. Ind. Inf. 2014, 10, 1992-2002.

8. Hintz, A.; Prasanna, U.R.; Rajashekara, K. Novel modular multiple-input bidirectional DC-DC power converter (MIPC) for HEV /FCV application. IEEE Trans. Ind. Electron. 2015, 62, 3163-3172. [CrossRef] 
9. Peyman, A.; Pierfederici, S.; Meybody-tabar, F.; Davat, B. An adapted control strategy to minimize dc-bus capacitors of parallel fuel cell/ultracapacitor hybrid system. IEEE Trans. Power Electron. 2011, 26, 3843-3852. [CrossRef]

10. Tao, H.; Kotsopulos, A.; Duarte, J.L.; Hendrix, M.A.M. Family of multiport bidirectional DC-DC converters. IEE Proc. Elect. Power Appl. 2006, 153, 451-458. [CrossRef]

11. Tao, H.; Duarte, J.L.; Hendrix, M.A.M. Three-port triple-half-bridge bidirectional converter with zero-voltage switching. IEEE Trans. Power Electron. 2008, 23, 782-792.

12. Krishnaswami, H.; Mohan, N. Three-port series-resonant DC-DC converter to interface renewable energy sources with bidirectional load and energy storage ports. IEEE Trans. Power Electron. 2009, 24, 2289-2297. [CrossRef]

13. De Donker, R.W.; Divan, D.M.; Kheraluwala, M.H. A three-phase soft-switched high power density DC/DC converter for high power applications. IEEE Trans. Ind. Appl. 1991, 27, 63-73. [CrossRef]

14. Naayagi, R.T.; Forsyth, A.J.; Shuttleworth, R. High-power DC-DC converter for aerospace applications. IEEE Trans. Power Electron. 2012, 27, 4366-4379. [CrossRef]

15. Engel, S.; Soltau, N.; Stagge, H.; De Doncker, R.W. Dynamic and balanced control of three-phase high-power dual-active bridge DC-DC converters in DC-grid applications. IEEE Trans. Power Electron. 2013, 28, 1880-1889. [CrossRef]

16. Farhangi, B.; Toliyat, H.A. A novel vehicular integrated power system realized through multi-port series AC link converter. IEEE Appl. Power Electron. Conf. Expo. 2015, 1353-1359.

17. Farhangi, B.; Toliyat, H.A. Modeling and analyzing multi-port isolation transformer capacitive components for onboard vehicular power conditioners. IEEE Trans. Ind. Electron. 2015, 62, 3134-3142. [CrossRef]

18. Prabhala, V.A.K.; Somayajula, D.; Ferdowsi, M. Power sharing in a double-input buck converter using dead-time control. IEEE Energy Convers. Congr. Expo. 2009, 2621-2626.

19. Li, Z.; Onar, O.; Khaligh, A.; Schaltz, E. Design and control of a multiple input DC/DC Converter for battery/ultracapacitor based electric vehicle power system. IEEE Appl. Power Electron. Conf. Expo. 2009, 591-596.

20. Gummi, K.; Ferdowsi, M. Double-input DC-DC power electronic converters for electric-drive vehicles-topology exploration and synthesis using a single-pole triple-throw switch. IEEE Trans. Ind. Electron. 2010, 57, 617-621. [CrossRef]

21. Bhattacharya, T.; Giri, V.S.; Mathew, K.; Umanand, L. Multiphase bidirectional flyback converter topology for hybrid electric vehicles. IEEE Trans. Ind. Electron. 2009, 56, 78-83. [CrossRef]

22. Nejabatkhah, F.; Danyali, S.; Hosseini, S.H.; Sabahi, M.; Niapour, S.M. Modeling and control of a new three-input DC-DC boost converter for hybrid PV/FC/battery power system. IEEE Trans. Power Electron. 2012, 27, 2309-2325. [CrossRef]

23. Liu, Y.C.; Chen, Y.M. A systematic approach to synthesizing multiinput DC-DC converters. IEEE Trans. Power Electron. 2009, 24, 116-127. [CrossRef]

24. Wu, H.; Ding, K.S.; Xing, Y. Topology derivation of nonisolated three-port DC-DC converters from DIC and DOC. IEEE Trans. Power Electron. 2013, 28, 3297-3307. [CrossRef]

25. Behjati, H.; Davoudi, A. A multi-port DC-DC converter with independent outputs for vehicular applications. In Proceedings of the 2011 IEEE Vehicle Power and Propulsion Conference (VPPC), Chicago, IL, USA, 6-9 September 2011; pp. 1-5.

26. Nahavandi, A.; Hagh, M.T.; Sharifian, M.B.B.; Danyali, S. Nonisolated multiinput multioutput DC-DC boost converter for electric vehicle applications. IEEE Trans. Power Electron. 2015, 30, 1818-1835. [CrossRef]

27. PSIM. Available online: http://powersimtech.com/products/psim/ (accessed on 6 February 2016).

(c) 2016 by the authors; licensee MDPI, Basel, Switzerland. This article is an open access article distributed under the terms and conditions of the Creative Commons by Attribution (CC-BY) license (http://creativecommons.org/licenses/by/4.0/). 